\title{
Oral counting sequences: a theoretical discussion and analysis through the lens of Representational Redescription
}

\author{
CHRONOULA VOUTSINA \\ SOUTHAMPTON EDUCATION SCHOOL, UNIVERSITY OF SOUTHAMPTON, U.K.
}

Telephone: 00442380592756

E-mail: cv@soton.ac.uk

\begin{abstract}
Empirical research has documented how children's early counting develops into an increasingly abstract process and initial counting procedures are reified as children develop and use more sophisticated counting. In this development, the learning of different verbal counting sequences that allow children to count in steps bigger than one is seen as an essential skill that supports children's mental calculation strategies. This paper proposes that the reification or refinement of the counting process that results to increased-in-sophistication use of counting is underlaid by the process of knowledge explicitation that the model of Representational Redescription postulates. The paper uses a case study to provide insight into the pathway that a 6-year-old child followed from learning how to verbally count in $2 \mathrm{~s}$ and $10 \mathrm{~s}$ to being able to use this knowledge for calculation purposes. The proposal is that knowledge of verbal sequences is redescribed in more explicit and accessible formats before children are able to connect their knowledge of the verbal counting with the goal of using the sequence for calculation. The discussion presented here queries the notion of spontaneity as an inherent element of the theory and discusses the role that social interaction may play in supporting knowledge redescription. If it is the case that children's knowledge of verbal counting sequences is redescribed into increasingly explicit formats before it can be applied for calculation then children need to be provided early in their education with structured activities that trigger knowledge redescription and support the necessary connections between counting, number structure and calculation.
\end{abstract}

Key words: counting sequences, oral counting, representational redescription, skip counting, addition, arithmetic 


\section{Introduction}

Oral counting is one of the elemental skills involved in the development of children's counting behaviour. Threlfall and Bruce (2007) define oral counting as "the ability of a child to produce in speech a correctly ordered string of numbers" (p. 64). Their work refers to children's oral counting of consecutive numbers from 1 . They consider oral counting to be a memory skill initially, as, in English the sequence of number words up to twelve does not follow a particular linguistic structure. It is when children learn the correct sequence of numbers beyond twenty that it is possible for them to notice and abstract certain linguistic patterns. Oral counting plays a fundamental role in overall counting behaviour as it supports the development of understanding of the number word system and of relations between quantities (Munn, 2008). Such understanding is essential for the development of mental arithmetic strategies that are based upon knowledge of quantity value (i.e., understanding that 53 is 50 add 3) (Thompson \& Bramald, 2002). Therefore, oral counting skills are significant for the development of children's number reasoning on the basis of number word sequences and quantities (Ellemor-Collins \& Wright, 2011).

In children's early encounter with number, counting, as an action, is initially performed on real world objects. Numerical development is based upon children's capacity to gradually move from associating numbers with real objects to seeing numbers as mathematical objects that can be manipulated through the flexible use of symbols (Gray \& Tall, 1994; Tall et al., 2001). In this process counting develops into a gradually more abstract endeavour. Initial counting procedures are compressed as children develop and use increasingly sophisticated and efficient counting as a calculation strategy (Gray, 2008). In line with this view Slavit (1999) proposes that the development of children's increasingly sophisticated counting strategies is the result of a "reification cycle" or refinement of the counting process with which children begin to see and use numbers as mathematical objects (p. 253). He argues that mathematics learning and understanding are built upon such "cycles of reification" within which mathematical objects are constructed as a result of students' meaning making activity.

In the field of developmental psychology Karmiloff-Smith's (1992) theoretical model of Representational Redescription proposes that knowledge that is already stored in the mind at initially implicit formats, progressively becomes more explicit and accessible through an internal process of representational change that results in elements of the same knowledge being re-represented at higher levels of abstraction (Karmiloff-Smith, 1992, 1993, 1994).

In this paper I am proposing that the reification or refinement of the counting process that results in the use of counting for calculation purposes in an increasingly sophisticated way is underlaid by the process of knowledge redescription and explicitation that the RR model postulates. A large body of 
literature has explored the development of children's oral counting skills (e.g., Bruce \& Threlfall, 2004; Fuson, 1992a; Fuson, 1992b; Threlfall, 2008), the development of children's counting competencies (e.g., Bialystok \& Codd, 1997; Fuson, 1992b; Gelman \& Greeno, 1989; Greeno, Riley $\&$ Gelman, 1984), and the use of counting as a calculation and problem solving strategy by children of different ages and attainment in mathematics (e.g., Lefevre et al., 2002; Siegler, 2006; Siegler \& Robinson, 1982; Sophian, Wood \& Vong, 1995). However, there has not been much attention to children's learning of oral counting in steps bigger than 1 (e.g., counting in steps of 2,5 or 10) and to how children develop this skill into processes that can support their calculations, despite the acknowledged significance of such counting skills (often referred to as "step" or "skip" counting) for mental calculation (Anghileri, 2008; Thompson, 2008). This paper aims to bring together theoretical notions developed in the fields of developmental psychology and mathematics education in discussing and documenting the process of knowledge explicitation that underlies children's learning of different counting sequences. It makes reference to a case study that provides insight into the pathway that a 6year-old child followed from learning how to verbally count in $2 \mathrm{~s}$ and 10 s to being able to use this knowledge for calculation purposes.

\section{Children's learning of oral counting sequences}

In her extensive research on young children's learning to count Fuson (1992a, 1992b) documented the developmental path that children between the ages of 2 and 8 years follow in producing the correct memorised sequence of number words. Fuson identified the types and points of error that occur by children of different ages at different sections of the counting sequence in English. She has also documented children's developmental trajectory in connecting their oral counting with the activity of counting for the purpose of ascertaining the cardinality of a set of objects. Further research by Threlfall and Bruce (2007), focusing on the development and types of errors that occur in children's learning of the counting sequence and involving pre-school children from a mix of socio-economic backgrounds in England, provided somewhat contrasting results in that it did not seem to provide supporting evidence for Fuson's (1992b) suggested age-related production of number strings and patterns of oral counting behaviour.

Clements and Sarama (2009) provide a concise overview of the development of counting and argue that quantitative thinking is contingent on oral counting. They state that at the early stages of learning to count children may be able to produce a "string" of words but "they do not even 'hear' counting words as separate words" (p. 21). The abilities to separate each counting word, start counting from any number (that Clements \& Sarama call the "Counter from $N[N+1, N-1]$ level"), skip count and then count the number words themselves when applying strategies such as the "counting on" strategy in addition are developed gradually. The gradual growth of children's counting capabilities is underlain by a gradually increased understanding that the ordered verbal counting sequence refers to 
quantities and that these quantities and associated numerical symbols can be manipulated to complete arithmetical procedures (Bialystok \& Codd, 1997).

Dowker, Bala and Lloyd (2008) consider the regularity of the spoken number system (i.e., the extent to which it provides a consistent representation of the base-10 system), and the degree of conformity between the written and the spoken number system as two of the linguistic factors that can influence aspects of mathematical development. Their results suggest that the structure of the counting system does not constrain or hinder the mathematical ability as a whole but can influence specific components of arithmetical performance. Aubrey (2003) views oral counting as one of the essential sub-skills and principles involved in learning to count and manipulate sets of objects, which, together with an understanding of the base-ten system provide a basis for addition and subtraction.

The use of counting as a strategy for solving addition problems and the gradual development of increased in sophistication counting strategies for addition have been the focus of extensive research (for a comprehensive account see Baroody \& Tiilikainen, 2003; Cowan, 2003). Initial unitary counting procedures are compressed as children develop and use increasingly sophisticated counting as a calculation strategy (Gray, 2009). An example of this is children's move from "Counting all with fingers" to "Counting on with fingers" when learning to add. To work out the answer to a question such as $5+4=$ ? "Counting all" involves counting 5 fingers $(1,2,3,4,5)$ and then 4 fingers $(1,2,3,4)$ and then counting all fingers together $1,2,3,4,5,6,7,8,9$. This initial counting strategy is gradually replaced by "counting on" where children begin their counting with 5 , and count on four $(6,7,8,9)$ (Fuson 1992a). According to Gray and Tall (1992), employing "counting on" indicates the compression of the process of counting into the concept of number. This more sophisticated counting strategy entails a "double-counting" process within which children have to keep track of how many number words are uttered when counting on 6, 7, 8, 9. Gray and Tall (1992) introduced the term "procept" to account for the capability to see number as a symbol that may evoke the process of counting or as a concept; that is as an entity and part of the number sequence. Tall and colleagues argue that observed differences in children's capability to shift their focus of attention from processes and actions to concepts and think about numbers as mental objects underlie success or failure in mathematics (Tall et al., 2001). In a similar vein of theoretical exploration, Slavit (1999) makes a theoretical proposal on how understandings of mathematical operations develop. Focusing the discussion on the operation of addition, Slavit delineates the essential aspects for the development of "operation sense" and proposes that the development of operation sense requires connections between addition and counting as its base process. Such connections may occur when the process of counting has been reified so that it can be thought of as a mathematical object itself rather than merely as an action on real-world objects. According to Slavit (1999) "The reification of counting leads to the notion of number as a permanent object" and enhances the meaning of the process of addition (p. 259). Both Gray and Tall's notion of "procept" and Slavit's notion of "reification of counting" postulate an 
underlying, essential process of abstraction that supports the development and use of counting as a calculation strategy.

Despite the significant work that has been done in researching young children's early learning of the unitary counting sequence and the use of this for the development of computation strategies, there has not been much focus on exploring the development of counting sequences other than counting in ones. Oral counting forwards and backwards in steps of 2, 5 and 10 and the capability to continue counting from any point of the counting sequence is a skill that is encouraged in the early years of primary education as it can help children with multiplication and division but also with developing partitioning strategies for addition and subtraction (Griffiths, 2008). In England, during a period of transition to a new National Curriculum for primary schools, learning to count in steps of 2, 3, 5, and 10 forms part of the statutory requirements and knowledge that children are expected to have developed by the end of Key Stage 1 (i.e., by age 6-7). Both in the old as well as new primary mathematics curriculum this skill is associated with children's developing recognition of number patterns in the number system (DfE, 2013; DfES, 2006).

Teaching strategies that are usually employed to support children's learning of oral counting sequences in steps bigger than 1 include rhythmic counting where children whisper interim numbers and say loudly the subtotal number. For example, when learning to count in 2 s a child may say 1, 2, 3, $4,5,6,7,8 \ldots$, where odd numbers are uttered quietly and even numbers (presented here in bold) are uttered loudly. Number tracks and number squares on which children highlight multiples of 2, 5, or 10 may also be used to support children's learning and the recognition of number structure and patterns visually (Anghileri, 2008; Montague-Smith \& Price, 2012).

Fluency in verbally producing and using different counting sequences supports the learning and application of "sequence-based" or "jump" addition and subtraction strategies that involve keeping one of two numbers that are to be added or subtracted as a whole and partitioning the other number. For example, knowledge of counting in steps of 10 can support the application of a mental strategy for addition that would involve the following steps: $27+12=27+10+2=37+2=39$. The use of such strategies has been mostly attributed to high-attaining children and has been found to be more effective and leading to fewer errors than other mental calculation approaches, for example, strategies that involve the partitioning of both numbers (e.g., $27+12=20+10+7+2=30+9=39$ ) (Beishuizen $\&$ Anghileri, 1998). "Sequence-based" strategies depend on knowledge of how to make steps and jumps along the number sequence and thus an understanding of the sequential structure of the number system (Ellemor-Collins \& Wright, 2007). It has been argued that a less developed structured representation of the number sequence is often seen in children of low attainment whose counting is restricted to counting in 1s (Munn, 2008). 
In an interview-based study that aimed at assessing 8-10 year old pupils' knowledge of the sequential structure of number Ellemor-Collins and Wright (2007) explored the range of low-attaining children's responses and difficulties in different groups of tasks that involved number sequences in ones and tens, incrementing and decrementing by ten and locating numbers. The researchers provided evidence for the significance and effectiveness of instructional designs that aim at helping children develop conceptual place value understanding by focusing on sequential structure and skills such as skip counting for enhancing children's understanding of number structure and mental computation (Ellemor-Collins \& Wright, 2011).

Counting sequences and skip counting evidently have a significant role to play in children's developing conceptualisation of number and number structure (Munn, 2008). Therefore, it is worth posing the question of whether learning and using counting sequences, other than the unitary counting sequence, are processes that are also undergoing a reification cycle towards increased generalisation, compression and abstraction similar to the processes postulated by the aforementioned theoretical views.

The purpose of this paper is to provide a theoretical perspective on the reification cycle that skip counting undergoes as children learn to produce the correct verbal sequence and move on to using knowledge of a particular sequence in computation. The paper proposes that knowledge that supports children's initial learning of different counting sequences is gradually redescribed in an increasingly explicit and manipulable format in line with the predictions of the theory of Representational Redescription. The theoretical proposal that this paper outlines is that it is this increased explicitation that underlies a process of reification of counting sequences until these can be connected with the operation of addition and used for additive computation. The following section presents the key theoretical constructs upon which the analysis of a case study is built.

\section{The theory of Representational Re-description}

\subsection{Knowledge explicitation}

Representational redescription (RR) is defined as "a process by which implicit information in the mind subsequently becomes explicit knowledge to the mind, first within a domain" (where a domain is a specific area of knowledge such as number or language) but also "across domains" (KarmiloffSmith 1992, p. 18). Building upon and extending Piaget's constructivist epistemology, KarmiloffSmith argues that the mind develops knowledge representations in interaction with the external as well as internal environment. During the internal and spontaneously-driven process of representational change elements of the same knowledge are re-represented at higher levels of abstraction (Karmiloff-Smith, 1993, 1994). 
According to the RR theory, cognitive change emanates from the learners' continuous search for understanding and control over their external environment and internal representations of knowledge. It is not necessarily failure that constitutes the primary motivation for cognitive change (KarmiloffSmith, 1984). Rather, the RR model seeks to describe the process of change as an internally-initiated and driven process during which knowledge representations become accessible and flexible leading to increased understanding and therefore behavioural flexibility. Even though failure may trigger changes at the behavioural level, it is procedural success rather than failure that is essential for knowledge reorganization and representational change to occur.

In the domain of mathematics Karmiloff-Smith (1992) suggests that children's representation of number is initially implicit and embedded in a representation of the counting procedure that is similarly implicit. The practice, mastery and gradual explicitation of the counting procedure leads to the development of an explicit representation of number. The RR theory postulates that the counting procedure has to be routinized and become automatic before it is redescribed into a more explicit format that allows children to access the different parts of the procedure.

Children may run procedures in their entirety and can use them in certain situations; however, separate components of the procedures may not be accessible or manipulable yet. For example, research has shown that young children may recount the same set of objects every time they are asked the question "how many?" rather than answering with the last number word of the sequence to indicate the quantity of the set that they have just counted. This behaviour may indicate a certain limitation in children's early counting knowledge, namely children's lack of appreciation of the principle of cardinality and of counting as a procedure for determining cardinality (Bryant \& Nunes, 2004). Within the RR framework this behaviour is an example of a procedure that is underlain by knowledge that is not yet accessible for cognitive manipulation and this explains why, on certain occasions, counting procedures need to be run afresh each time when the question 'how many' is asked, even when a set of objects has just been counted.

Subsequent research focusing on the development of 9-13 year-old children's understanding of mathematical relations has provided evidence that supports the idea of representational redescription as a mechanism that underlies knowledge construction when learners already have a moderately effective representation and understanding of the task in hand (Dixon \& Bangert, 2005). This research has suggested that redescription works when information is activated by correctly executing procedures in a tight temporal sequence (Dixon \& Bangert, 2005, p. 84). Dixon and Bangert (2002, 2005) found no developmental differences in the process of redescription between children in the 9-13 age range and suggested that the process of recescription might underlie knowledge construction at very young age. In exploring micro-developmental changes in 5-6 year old children's successful problem solving behaviour, Voutsina (2012) applied the RR model as an analytical framework and 
documented post-success changes that occur as children develop organisation-oriented problem solving strategies in a multi-step addition task. The findings supported the idea for success-driven procedural and conceptual changes but also raised questions about certain features of the RR model such as the hypothesis for a U-shape curve and regression that may be observed in the process of knowledge explicitation (please see description of the RR model and associated hypotheses in section $3.2)$.

The idea of knowledge explicitation in the domain of number is not new. Bialystok and Codd (1997) argue that children's gradual construction of the concept of cardinality is regulated by a process whereby implicit counting knowledge becomes explicit when children begin to connect numbers with quantities as well as a process of gradually increased control of attention to the object and product of counting. In their 1984 article on children's conceptual competence in counting Greeno, Riley and Gelman cite Rozin's (1976) proposition that cognitive growth entails a process that renders implicit knowledge explicit and relate this proposition to Piaget's notion of reflective abstraction. According to Greeno et al. (1984) explicitation of counting-related concepts requires "a process of reflective abstraction about processes which Karmiloff-Smith (1979) has discussed" (p. 141).

There is a significant difference between previous references to knowledge explicitation and Karmiloff-Smith's Representational Redescription (RR) theory. Karmiloff-Smith observes, positions and analyses knowledge explicitation in the part of learning and development that takes place following successful performance in a given task rather than in the part of an individual's learning and developmental trajectory that leads to initial procedural mastery and successful performance in completing particular tasks. This feature of the theory differentiates it from other theorizations of mathematical thinking and development that depict the developmental trajectory from initial levels of weaker conceptualization and also limited in some aspects, or erroneous task performance, to levels of increased abstraction and understanding (see for example Resnick's (1992) developmental model of mathematical thinking or from the field of mathematics education Mulligan \& Mitchelmore's (2009) levels of mathematical structure). The inherent idea of procedural and conceptual changes and knowledge explicitation that follow success makes the theory of Representational Redescription an interesting theoretical lens for exploring changes that occur following a child's initial mastery of an oral counting sequence (in the case of this paper, skip counting sequences). The following section describes the RR model of phases of knowledge redescription.

\subsection{The RR model}

The RR model is process-oriented and describes phases of post-success behaviour as well as levels of explicitness at which the learner's knowledge is re-described and re-represented. The phases of knowledge redescription are not age-related and the theory does not assume domain-general changes. 
The model contends that when children are involved in a problem-solving situation, they pass through the same recurrent phases within various micro-domains (for example, counting is a micro-domain within the mathematics domain) and also across different domains.

At the "Procedural Phase" the child's behaviour is "success-oriented" and generated by adaptation to external stimuli. Procedural success is achieved by adapting to positive or negative external feedback. At the end of this phase automatic procedures are consolidated as the learner reaches "behavioural mastery" (Karmiloff-Smith, 1984, p. 19). The procedures that are employed at this phase of problem solving behaviour, though successful, consist of behavioural units that are not connected to each other nor organised. Hence, successful, but isolated, problem solving procedures are applied for each part of the problem.

At the "Meta-procedural Phase" the child's internal representations are brought into focus. The learner begins to have access to separate knowledge components and procedures become the "cognitive units of attention" (Karmiloff-Smith, 1984, p.43). Behaviour at this phase is "organisation oriented" rather than "success oriented". Due to the focus on organizing and connecting the previously isolated procedures into a single representational framework the child may ignore environmental information and feedback and this may result in errors as children attempt to organize and connect the previously unconnected procedures. The regression that may be observed at the behavioural level does not also imply regression at the representational level as children move beyond procedural success, to theory building and to generating a unified approach applied to different parts of the problem (Karmiloff-Smith, 1984, 1992).

At the "Conceptual Phase" the interaction between external information and internal representations is balanced. "Phase 3 is the result of the re-organizational processes at work in phase 2 which, once consolidated, can take environmental feedback into account without the overall organization being jeopardized" (Karmiloff-Smith, 1984, p. 44). During this phase the interaction between external data and internal representations is regulated and balanced as a result of the search for both internal and external control. Even though children's behaviour is successful as in the "procedural phase", the knowledge representations that sustain children's behaviour in phase 3 are richer and more coherent (Karmiloff-Smith, 1984).

In this paper Karmiloff-Smith's (1992) theory of phases of representational redescription is used as the theoretical lens for tracking and interpreting observed changes that occurred as Sara, a 6-year-old child, practiced skip counting and related addition calculations as part of homework activities over a period of three months (the name is a pseudonym). The table below presents a description of observed behaviours that were considered as indicating characteristics of each of the RR phases and that knowledge of the counting sequence was gradually redescribed in terms of its accessibility and explicitness. 
Table 1: Description of counting behaviour in each of the RR phases.

Procedural phase

Successful production of the correct verbal sequence. Observed inflexibility of counting behaviour (e.g. inability to continue counting from any number of the sequence). Knowledge of the sequence is not used for calculation.

Metaprocedural phase

Separate components of the sequence become accessible. The child demonstrates ability to start counting from any point of the sequence. She begins to observe numerical patterns, however the sequence is not used for calculation yet and direct connections with addition have not been made. Regression to errors were not observed in the learning of the two sequences within this phase even though this is predicted by the theory of Representational Redescription. This point is discussed as part of the analysis of the case and the implications for theory and research.

Conceptual phase

Successful production of the correct verbal sequence with observed flexibility of counting behaviour. The child demonstrates ability to start counting from any point of the sequence. She abstracts numerical patterns, begins to generate rules (e.g. a $n+2 / n-2$ rule in the case of the counting-in-twos sequence) and uses this to answer calculation questions.

\section{Case Study}

\subsection{Context of the case}

The case study discussed here was not designed with the pre-specified research aim of investigating children's learning of skip counting sequences. The theoretical exploration and query related to the cycle of reification that this learning might be going through was triggered after observing and following my 6-year-old daughter's practice of counting in $2 \mathrm{~s}$ (in this case, the sequence of even numbers) while completing homework tasks. Observing Sara's developing knowledge of this particular sequence triggered thoughts about how her observed behaviour could possibly be interpreted on the basis of the theory of representational redescription. I then began to keep a record of episodes related to Sara's counting in $2 \mathrm{~s}$ and 10 s that occurred during the weekly homework tasks and skip counting practice at home, over a period of three months.

In this sense, the presentation of Sara's trajectory in learning to count in steps of 2 and 10 is not the standard type of case study that would be designed as part of an empirical research project. Sara is a typical case in the sense that she is a typically developed child who follows the standard curriculum that is taught in primary schools in England and she is completing the same homework as other children in her class. The episodes that are presented here can be considered as typical for Sara. In my 
dual role as parent who aims to support their child's learning and researcher with an interest in young children's mathematical learning and development, I often extend the dialogue that takes place between Sara and me during homework with questions that are not necessarily prescribed as part of the school-set task. Thus, the episodes presented below are part of Sara's natural learning experiences at home. The extent to which this type of parent-child interaction can be seen as typical of home learning situations in general cannot be ascertained as parent-child interactions in home learning situations are essentially natural and fluid with varying parent and child goals.

Before recording our homework discussions I explained to Sara that I would like to understand better and write about her counting and the way she talks about numbers. Sara, who is familiar with what I do, expressed great excitement about this prospect. At a later stage she read all the extracts of dialogue that I had collated. I explained to her that I have read many books about how children learn to count and I am trying to look at the way she is learning to count in $2 \mathrm{~s}$ and $10 \mathrm{~s}$ because there is not much written about this kind of counting in what I have read.

Situated in this context, this case is used to probe and illustrate particular points of theoretical discussion and query in relation to representational redescription as an underlying learning mechanism. The paper highlights significant parts of the theory that can provide a useful analytical frame for understanding individual pathways of counting knowledge development that follow initial procedural success and which are worth of further empirical exploration.

In the extracts presented below, numbers are written using numerical notation in questions that include sums (this is to help the reader follow the sequence of questions with ease) while number words are used when depicting Sara's (S) verbal counting.

\subsection{Sara's skip-counting}

At the early stages of her learning Sara memorised quickly the first part of the counting sequence in 2s up to 8 and sometimes 10 and she liked repeating this sequence quite frequently. To continue her oral counting in $2 \mathrm{~s}$ from 8 or 10 she would whisper the intermediate odd numbers, say loudly the even numbers and count on like this up to 100 . She applied the practice strategy that she had learnt at school, that is, rhythmic counting that involved whispering interim numbers and saying loudly the subtotal number.

S: Two, four, six, eight..., nine (whispers), ten, eleven, twelve, thirteen, fourteen, fifteen, sixteen, (whispering numbers that appear in italics here). (Sara explains): You just.... skip one, you do it in two like this... because you miss one and you go to the other one.

When she had developed fluency in her oral counting in multiples of 2 forwards and backwards, the following episode occurred. 
S: Two, four, six, eight, ten, twelve, fourteen, sixteen, eighteen, twenty.... twenty-two, twenty-four, twenty-six, twenty-eight, thirty, thirty-two.... (continues up to one hundred). I know how to count in $2 s$ !

C: Can you do it again but... what if you start from twelve...?

S: Twelve... (she does not continue).

C: Twelve and then? How would you go on in 2 s?

S: Twelve, thirteen, fourteen, fifteen, sixteen (whispering intermediate numbers).

In the above episode Sara seemed to retreat to uttering intermediate numbers when I asked her to start her counting in 2 s from 12 even though by that point she could produce verbally the correct counting sequence up to 100 , starting from 0 , with fluency. I then asked:

C: What's 24 add 2?

S: Twenty-four...twenty-five, twenty-six.

C: Great. So what's 6 add 2?

S: Eight. I know this. Six add two is eight, I know.

C: What about 26 add 2 ?

S: Twenty-six... twenty-eight!

C: How did you know?

S: You go on two after twenty-six is twenty-seven, twenty-eight.

C: Ok, what about... 38 take away 2.

S: Thirty-eight....thirty-six.

C: How did think about it in your head?

S: I went backwards thirty-eight, thirty-seven, thirty-six.

The above two episodes seemed to indicate that even though Sara could orally produce the counting sequence with no errors and with fluency, she did not seem to be able to start counting in twos from any given number of the sequence with ease. Furthermore, Sara's verbal counting behaviour and verbal reports indicated that even though she had developed procedural mastery in counting in twos from two, she did not seem to have access to the different components of the sequence and did not use her knowledge of the number sequence to retrieve sums that involved adding 2 . On the basis of the RR model predictions of learners' behaviour at the "procedural" phase, Sara's observed behaviour could be interpreted as being supported by well-functioning procedures that needed though to be run afresh every time because they consisted of successful but non-well connected behavioural units.

As Sara continued practicing her counting in twos forwards and backwards she soon developed capability of starting her oral counting in twos from any even number. 
C: What about starting from .... 58?

S: Fifty-eight.... sixty, sixty-two, sixty-four, sixty-six, sixty-eight, seventy, seventy-two...

C: Let's count in 2s starting from... 24.

S: Easy... twenty-four, twenty-six, twenty-eight, ... thirty, thirty-two, thirty-four....

C: Can you start from any number?

S: Yeah... it's two, four, six, eight and then ten and then it goes twelve, fourteen, sixteen, eighteen, it's like two, four, six but with the 1 at the front and then 2 in front...

C: Why do they have a 1 at the front and then 2 at the front?

S: Because... that's.... how it goes to one hundred. Uhm... twenty and then you do twenty-two, twenty-four, twenty-six, twenty-eight... thirty, thirty-two, thirty-four, thirty-six, thirty-eight, forty, forty-two, forty-four... it's all the same (emphasises number words in italics).

C: What's the same?

S: It goes like two, four, six again.

Sara's explanations indicated that she had noticed and used the repetitive numerical and verbal pattern of the sequence to help her continue her counting. This behaviour could be interpreted as indicative of a "metaprocedural" phase at which separate components of a procedure are becoming accessible and the procedure is less rigid. Sara's reference to the description of the numerical pattern and explanation of number structure indicates a move towards explicitating the knowledge representations that support the structure of the counting sequence. However, she would still count on 2 uttering the intermediate numbers when asked to add 2 on a given even number mentally.

C: What is 24 add 2 ?

S: Twenty-four... twenty-five, twenty-six! It's twenty-six.

This could be because Sara found it preferable or easier to think in this way or could indicate that her oral counting in $2 \mathrm{~s}$ had not been fully connected with addition yet as her knowledge was still under a process of redescription that had not reached the phase where explicit interrelations between this newly learned counting and the conception of addition were established and consolidated. It was interesting to observe how at a later phase, Sara's explanations began to indicate that she started making explicit reference to the numerical counting sequence in order to retrieve the answers to sums that involved adding 2 to another even number.

C: I wonder how fast you can give me the answer to these sums: 34 add 2?

S: Thirty-six!

C: 68 add 2?

S: Seventy! 


\author{
C: How do you know? \\ S: I remembered them.... seventy is after sixty-eight when you count in 2 s.
}

The above extract is an example of Sara's verbal reports that indicated that at that point her knowledge of the sequence of even numbers might have led to the development of a $n+2 / 2+n$ rule similar to the number-after knowledge that according to Baroody (1995) children develop when learning the unitary counting sequence. According to Baroody the number-after rule implies that children recognise that the sum $7+1$ is the number after 7 and so this makes $1+n$ and $n+1$ number combinations easy to learn. In the above explanation Sara appeared to have abstracted the observed numerical pattern that can lead to the generation of a rule. Her response also indicated an explicit connection between the particular counting sequence and its use for retrieving additive combinations. This seemed to be a significant conceptual achievement as at this phase Sara's knowledge of the particular numerical sequence seemed to be supported by flexible procedural representations, conceptualisation of number and sequence structure and capability to use and connect this knowledge with the goal of retrieving the answer to +2 addition sums. Within the RR framework the connection of these different pieces and kinds of knowledge would be considered as indications of a "conceptual" phase.

Sara's learning of counting in 10s seemed to follow a slightly different trajectory. While practicing the sequence of multiples of 10 from 0 to 100 Sara seemed to be focusing on structure from the early stages of learning this sequence. At points of difficulty or hesitation she would explicitly refer to the structure of the number system to help her continue her oral counting.

S: Ten, twenty, thirty, forty, fifty, sixty... (whispering: ... six...seven... )... seventy ... eighty, ninety, a hundred!

Sara seemed to hesitate when reaching number 60 . Her whispering of numbers 6 and 7 indicated that she was referring to the sequence of numbers up to 10 and her knowledge of structure to go beyond this point of hesitation and determine the numbers that should follow 60 in the sequence of multiples of 10. At a later episode Sara counted in 10 s up to 100 and backwards without hesitation. When asked to start her counting from any number of the sequence she had no difficulty to do so. She completed related written sums such as $30+10=$ that were part of school-set homework with not much difficulty either.

C: So how did you know it is 40 ?

S: Just... I know. Cause forty comes after thirty down the number square.

C: What if you had to add 30 and 20 ?

S: ... thirty, forty, fifty! We did this.... with Miss T (her teacher) because you have to go two down. 
C: Why do you have to go down two?

S: Because it's twenty so... you do two steps?

C: Why do you have to do 2 steps for 20 ?

S: Because... you .... you do one ten and ten (makes a gesture that shows going down two times).

Sara's response indicated again reference to her knowledge of the number system structure which had been supported by use of the "hundred square" at school. The "hundred square" is a grid of numbers from 1 to 100 arranged in rows of ten. In the "hundred square" the multiples of ten appear vertically in the far right column of the table. Her reference to the square seemed to be supported by Sara's knowledge of how many tens are in numbers such as twenty. When adding multiples of ten Sara applied her knowledge of the multiples-of-ten sequence as well her knowledge of number structure and quantity. This knowledge seemed to be well connected with the procedural aspect of using a resource well-known to her and its structure to help her add together multiples of ten.

Even before becoming fluent in producing the verbal sequence Sara was able to apply her knowledge of relations between numbers (i.e., the relation between 6 and 7 in the sequence of numbers up to 10 with numbers 60 and 70 in the sequence of multiples of ten) in order to get beyond points of error or hesitation. The verbal sequence in this case was well connected with the goal of adding multiples of ten even before the sequence was fluently learnt (i.e., before a consolidated successful output) and this connection was supported by clear conceptualisation of structure and quantity. In this case Sara's learning did not seem to follow a pathway that indicated a move from procedural to meta-procedural and finally conceptual phases as the RR model predicts. It could well be that such a pathway was not captured in the episodes that were recorded. Or it could also be that in this case conceptual understandings about the numbers involved in this sequence had preceded, overlapped with or informed the development of procedural representations. Research by Rittle-Johnson, Siegler and Alibali (2001) and Rittle-Johnson and Koedinger (2009) has shown that the development of procedures and concepts does not follow a predetermined and specific sequence and in fact the development of conceptual knowledge may precede and influence the development of procedures in the learning of particular topics and notions in mathematics.

It was interesting then to make observations on Sara's practicing of counting in 10s from any given number between 1 and 9. It should be noted that the "hundred square" that Sara refers to in the extract below was not used and was not visible when the following interaction took place. It is not clear whether Sara visualised the "hundred square" in her mind to support her thinking when challenged by some of the questions.

C: So which number do you want to start from? 
S: Five. I know it. Five, fifteen, twenty-five, thirty-five, forty-five, fifty-five, sixty-five, seventy-five, eighty-five, ninety-five, a hundred and five! (Also counts backwards). It's easy it all finishes with five.

All the numbers.

C: Why is that?

S: It.... how it goes. I will do the 6 now.

C: Before you do this, what's 45 add 10 ?

S: (Looks at fingers of both hands and counts on in steps of one from 45 to 55) forty-six, forty-seven, forty-eight, ...... fifty-five.

C: Great. Could you perhaps have thought about it differently so that you don't have to count 10 fingers?

S: No.

C: Well, when you counted in 10s from 5, how did you count?

S: Five, fifteen, twenty-five, thirty-five, forty-five, fifty-five ...

C: So you said forty-five and then fifty-five so when you count in tens you are adding ten every time isn't that right?

S: Yeah.... You add ten.... you go down the line.

C: What line?

S: On the hundred square.

$\mathrm{C}$ : Ok, so what is 65 add 10 ?

S: Uhm..... so I do it like counting in 10s? (she takes some time)..seventy-five.

C: Well done, how did you think about that?

S: I counted ... Five, fifteen, twenty-five, thirty-five, forty-five, fifty-five, sixty-five, seventyfive......

In this episode it was clear that Sara did not make an immediate connection between her counting in 10 s from 5 and a related sum. I encouraged her to use her knowledge of the sequence in an explicit way to make her see the connection. With her question: "so I do it like counting in 10s?" it was not clear whether she had actually conceptualised the connection that I had tried to make her see between the oral sequence, the number square and addition, or she was trying to do what I had prompted her to do. Her subsequent explanation showed that at that phase she needed to count from the beginning of the sequence up to the point that would help her determine the answer. In terms of the RR model this could be considered as indication of procedure-like representations that needed to be run in their entirety and also lack of connections between verbally producing the sequence and the operation of adding 10 to any number of the sequence. In RR terms this behaviour seemed to have the characteristics of the "procedural" phase. 
As Sara continued practicing her counting in 10 s, a distinction between a "meta-procedural" and "conceptual phase" was difficult to make. Her fluency in counting correctly in tens from any number was observed almost together with her ability to make connections with addition when asked to work out related sums.

C: What if I asked you to count in 10 s from.... 47 ?

S: uhm... forty-seven, fifty-seven, sixty-seven, seventy-seven, eighty-seven, ninety-seven, one hundred and seven.

C: What's 12 add 10 ?

S: Twenty-two.

C: What about 63 add 10 ?

S: Uhm... sixty... seventy.... seventy three.

C: How did you work it out?

S: Seventy-three is after sixty-three.

Sara's responses indicated fluency in the verbal sequence together with ability to access separate parts of the sequence and use this to work out related sums. Her behaviour provided indications of knowledge that was adaptable to the task.

S: (Working out the answer to a written sum $25+30=$ ) She looks down to her fingers, she raises three fingers of her right hand- one at a time - and then writes down the answer 55).

C: How did you work it out?

S: I counted like... uhm... thirty-five, forty-five, fifty-five (raises one finger at a time as she utters these numbers), it's... add thirty.

Within the "conceptual phase" which assumes rich and consolidated knowledge representations Sara's observable behaviour and verbal reports, as in the above episode, provided indication of a "double counting" process similar to what Tall et al. (2001) describe whereby children keep track of the number words uttered when applying counting-on in addition. Such an approach indicates increased sophistication and the ability to see and use number as part of the counting sequence and process as well as a manipulable entity.

\section{Analysis of the theoretical and research implications}

Observed changes in Sara's knowledge and use of verbal counting indicated that her verbal counting was gradually "reified" as she moved from producing the correct verbal sequence as a whole, to being 
able to access separate parts of the sequence and subsequently use this knowledge for retrieving addition combinations. This pathway of changes has many of the characteristics of phases of behaviour and of knowledge state that are postulated by Karmiloff-Smith's $(1984,1992)$ theory of Representational Redescription (RR). The theory supports the view that it is not failure that constitutes the primary motivation for cognitive change; rather, cognitive change emanates from the learners' continuous search for understanding and control over their external environment and internal representations of knowledge (Karmiloff-Smith, 1984). In this process the learner's knowledge is redescribed and re-represented during recurrent phases that mark post- success behaviour.

Sara's case indicated that her learning of three different sequences (counting in $2 \mathrm{~s}$-sequence of even numbers, counting in $10 \mathrm{~s}$ - sequence of multiples of 10 , and counting in 10 s from any number) followed pathways of slightly different observed behaviours. In the case of counting in $2 \mathrm{~s}$ and counting in 10s from any number Sara reached a phase where her correct and fluent production of the verbal sequence was observed with a certain degree of rigidity, difficulty in accessing separate parts of the sequence and lack of connection between the counting sequence and related addition sums. In the case of both these sequences this phase had the characteristics of the "procedural" phase that the RR model postulates. Sara's continuing practice and work on these sequences gradually led to a phase where separate parts of the sequence were accessible but spontaneous connections between her skip counting and the operation of addition had not been made yet. This could be considered as indication of a post-initial success, "meta-procedural" phase at which Sara gradually began to work upon connections between her existing and new knowledge in the sense that she started talking about and working upon the structure of the sequence in relation to her knowledge of number structure. She was not yet at a phase where she would apply her knowledge of this counting for the goal of working out sums or retrieving additive combinations. It is noteworthy however that in contrast to the RR model's predictions Sara's counting behaviour at this phase was not accompanied by regression to unsuccessful performance. Rather, this phase seemed to be characterized by not fully constructed and consolidated connections between new and existing parts of her knowledge.

When Sara had begun to connect her knowledge of the counting sequences with the goal of retrieving addition combinations, her verbal counting behaviour and explanations gave indication of increased explicitness and connection between the procedural, conceptual and utilization aspects of her counting. This move had characteristics that would allow one to assume an underlying process of redescription and explicitation of knowledge such as the one the RR model proposes within the "conceptual" phase.

Different observations were made in relation to Sara's learning of the multiples-of-ten sequence. Sara's behaviour and explanations provided indications of connection between her still developing knowledge of the sequence, her existing knowledge on the structure of the number system as well as with her knowledge on relationships between quantities even before she had reached a phase of 
success and fluency in producing the correct verbal sequence. The episodes that were recorded did not capture a distinguishable sequence of phases such as the ones that the RR model proposes. It could be that these episodes simply did not capture a process that had already occurred or it could be that the learning process in this case followed a different trajectory. Karmiloff-Smith's model provides a clear delineation of a process of knowledge redescription that progressively leads to conceptual development on the basis of redescription of knowledge that supports the learner's initially procedural experience. However it has been evidenced that children's pathways of learning mathematics do not necessarily follow such a pathway from a procedural to a conceptual state of knowledge (RittleJohnson et al., 2001). In the case of Sara's counting in multiples of 10, I would suggest that there was something qualitatively different about the learning of this sequence possibly because Sara had already constructed knowledge of structure and quantity relations in connection with these particular numbers (i.e., multiples of ten) before she had learnt the verbal counting sequence.

Accepting that learning and knowledge construction may follow different trajectories raises the question of what is the role that representational redescription plays in possibly different individual learning trajectories as a process that instigates and underlies cognitive change. Star (2007) and Star and Stylianides (2013) argued that knowledge, procedural or conceptual, may be superficial or deep and so it is essential to consider knowledge 'quality' and not only knowledge 'type' when discussing and exploring elements of mathematical proficiency. Baroody, Feil and Johnson (2007) also argued for the need to consider different qualities of procedural and conceptual knowledge in the study of their interrelation, such as the depth, accuracy, structure and abstractness. Accepting the RR theoretical proposition that knowledge explicitness and accessibility are two fundamental attributes of knowledge that cognitive change relates to, future research is needed to explore whether the notion of representational redescription, as a process that renders knowledge progressively more explicit and accessible, underlies changes that relate to aspects of the quality of knowledge (be it procedural or conceptual) and not only to a move from one type of knowledge representations to another.

\section{Conclusion}

I would propose that movement to using knowledge of the verbal counting sequences for calculation requires redescription of a child's knowledge of such counting sequences into more accessible formats so that components of the sequences can be focused on individually and used in calculation. In the field of mathematics education Slavit (1999) argues that the development of operation sense in addition involves the reification of counting to a sufficient degree and requires interrelations of flexible conceptions by the learner. Citing Steffe and Oliver (1996), Slavit (1999) proposes that a generalised understanding of addition begins with understanding "of the operations involved in producing a sequence of units, uniting the units of the sequence together into a composite unit, and decomposing this composite unit into its constituent parts" (p. 259). Analysis of the episodes of the 
case study presented here indicates that the learning of new, more sophisticated, counting sequences and the capability to compose and decompose these newly learnt sequences into their constituents parts and use them for the purposes of calculation develops gradually. Viewing this process of reification through the lens of the theory of knowledge redescription - a notion that originates from developmental psychology - brings together theoretical notions from different fields in seeking to explore and understand processes that underlie advances in early number learning. In doing so this paper contributes to theory by defining 'reification', as it applies to counting sequences, as a process that involves knowledge redescription, that is a move towards increased knowledge accessibility and explicitation, which in turns supports connections between a particular sequence and the operation of addition.

The original conception of the theory of representational redescription suggests an internally-driven process of reflection that occurs spontaneously in children, without adult questioning (KarmiloffSmith, 1984). However, I would argue that there is nothing in the notion of post-success reorganisation of knowledge and work upon one's own existing representations that would necessarily preclude the possibility of knowledge redescription being triggered and supported by purposeful learning and teaching interactions. Consequently, the extent to which spontaneity needs to be an essential element in the theory of representational redescription needs to be revisited.

Learning to count is a goal-directed activity and a socio-cognitive developmental construction (Sophian, 1997). Therefore counting, as a social activity, needs to be explored beyond the classroom as social experience at home and most importantly, the nature of this experience has been found to play a significant role in the development of early number skills that are fundamental in the development of children's numerical cognition (Bruce \& Threlfall, 2004). Within the episodes of parent-child interaction discussed here the parent had the clear goal of supporting the child's learning. Furthermore, within this interaction the child made reference to tools that were familiar to her from the school context, such as the "hundred" square. From a socio-cultural approach to learning within which "...how the mind works is dependent on the tools at its disposal" (Bruner, 2009, p.160), it would be argued that the questions asked by the adult in this case and reference to particular tools challenged the child's thinking, triggered particular connections and supported Sara's move towards increased conceptualisation of the counting sequences.

Sophian $(1997,2009)$ emphasises that particular experiences impact on children's numerical thinking. In her argument about the bi-directional relation between competence and performance she refers to Vygotksy's (1978) notion of “zone of proximal development” to support the point that parents and others play a significant role in introducing children to activities and learning goals. She therefore highlights the need for research that collects data from young children's everyday numerical experiences with the aim at exploring processes that lead to advances in early numerical knowledge 
within different contexts and patterns of interaction, including parent-child and teacher-child interactions. A focus on analysing particular features of the parent-child interaction within the presented case was beyond the scope of this paper. However, in probing theoretical discussion and query, the case presented here also addresses the need to study everyday numerical experiences and suggests that research and education could usefully explore the role that different learning environments may play in triggering and supporting knowledge redescription as well as in influencing and promoting learners' post-success search for increased and in-depth understanding.

\section{Acknowledgements}

I am thankful to my daughter for sharing with me her knowledge and thoughts about numbers and allowing me to write about our maths discussions in this paper. I would like to express my thanks to my colleague Keith Jones for his feedback on an earlier draft of the paper, to the editors and the four anonymous reviewers for their very constructive comments and suggestions on how this work can be taken forward.

\section{References}

Anghileri, J. (2008). Uses of counting in multiplication and division. In I. Thompson (Ed.), Teaching and Learning Early Number (pp. 110-121). Maidenhead: Open University Press.

Aubrey, C. (2003). "When we were very young": The foundations for mathematics. In I. Thompson (Ed.), Enhancing Primary Mathematics Teaching (pp. 43-43). Maidenhead: Open University Press. Baroody, A. (1995). The role of the number-after rule in the invention of computational short cuts. Cognition and Instruction, 13, 189-219.

Baroody, A.J., \& Tiilikainen, S.H. (2003). Two perspectives on addition development. In A.J. Baroody \& A. Dowker (Eds.), The development of arithmetic concepts and skills (pp.75-125). Mahwah: Lawrence Erlbaum Associates.

Baroody, A.J., Feil. Y., \& Johnson, A.R. (2007). An alternative reconceptualisation of procedural and conceptual knowledge. Journal for Research in Mathematics Education, 38(2), 115-131.

Beishuizen, M., \& Anghileri, J. (1998). Which mental strategies in the early number curriculum? A comparison of British ideas and Dutch views. British Educational Research Journal, 24(3), 519-538. Bialystok, E., \& Codd, J. (1997). Cardinal limits: evidence from language awareness and bilingualism for developing concepts of number. Cognitive Development, 12, 85-106.

Bruce, B., \& Threlfall, J. (2004). One, two, three and counting. Educational Studies in Mathematics, $55,3-26$. 
Bruner, J. (2009). Culture, Mind and Education. In K. Illeris (Ed.), Contemporary theories of learning. Learning theorists ... in their own words (pp. 159-168). London: Routledge.

Bryant P., \& Nunes, T. (2004). Children's understanding of mathematics. In U. Goswami (Ed.), Childhood Cognitive Development (pp. 412-439). Oxford: Blackwell Publishing.

Clements, D. H., \& Sarama, J. (2009). Learning and teaching early math. Oxon: Routledge.

Cowan, R. (2003). Does it all add up? Changes in children's knowledge of addition combinations, strategies and principles. In A.J. Baroody \& A. Dowker (Eds.), The development of arithmetic concepts and skills (pp.35-74). Mahwah: Lawrence Erlbaum Associates.

DfE (Department for Education). (2013). Mathematics programmes of study: Key stages 1 and 2. National curriculum in England. Department for Education.

DfES (Department for Education and Skills). (2006). Primary Framework for Literacy and Mathematics. Norwich: DfES.

Dixon, J. A., \& Bangert, A. S. (2005). From regularities to concepts: the development of children's understanding of mathematical relation. Cognitive Development, 20, 65-86.

Dowker, A., Bala, S., \& Lloyd, D. (2008). Linguistic influences on mathematical development: How important is the transparency of the counting system? Philosophical Psychology, 21(4), 523-538. Ellemor-Collins, D., \& Wright, R. (2007). Assessing Pupil knowledge of the sequential structure of numbers. Educational and Child Psychology, 24(2), 54-63.

Ellemor-Collins, D., \& Wright, R. (2011). Developing conceptual place value: Instructional design for intensive intervention. Australian Journal of Learning Difficulties, 16(1), 41-63.

Fuson, K. C. 1988. Children's counting and concepts of number. New York: Springer-Verlag. Fuson, K. C. (1992a). Research on whole number addition and subtraction. In D. Grouws (Ed.), Handbook of Research on Mathematics Teaching and Learning (pp. 243-275). New York: Mac Millan.

Fuson, K. C. (1992b). Relationships between counting and cardinality from age 2 to 8 . In J. Bideau, C. Meljac \& J-P. Fisher (Eds.), Pathways to Number: Children's Developing Numerical Abilities (pp. 127-149). Hillsdale: New Jersey: Lawrence Erlbaum Associates.

Gelman, R., \& Greeno, J. G. (1989). On the nature of competence: principles for understanding in a domain. In L. B. Resnick (Ed.), Knowing, Learning and Instruction: Essays in honor of Robert Glaser (pp. 125-186). Hillsdale, New Jersey: Erlbaum.

Gray, E. (2008). Compressing the counting process: strengths from the flexible interpretation of symbols. In I. Thompson (Ed.), Teaching and Learning Early Number (pp. 82-93). Maidenhead: Open University Press.

Gray, E., \& Tall, D. (1992). Success and failure in mathematics: the flexible meaning of symbols as process and concept. Mathematics Teaching, 142, 6-10.

Gray, E., \& Tall, D. (1994). Duality, ambiguity and flexibility: a proceptual view of simple arithmetic. Journal of Research in Mathematics Education, 26(2), 115-141. 
Greeno, J. G., Riley, M. S., \& Gelman, R. (1984). Conceptual competence and children's counting. Cognitive Psychology, 16, 94-143.

Griffiths, R. (2008). The family counts. In I. Thompson (Ed.), Teaching and Learning Early Number (pp. 47-58). Maidenhead: Open University Press.

Karmiloff-Smith, A. (1979). Micro- and macro-developmental changes in language acquisition and other representational systems. Cognitive Science, 3, 91-118.

Karmiloff-Smith, A. (1984). Children's problem solving. In M. E. Lamb, A. L. Brown \& B. Rogoff (Eds.), Advances in developmental psychology (pp. 39-90). Hillsdale, New Jersey: Lawrence Erlbaum Associates.

Karmiloff-Smith, A. (1992). Beyond modularity: a developmental perspective on cognitive science. London: The MIT Press.

Karmiloff-Smith, A. (1993). What's special about the development of the human mind/brain? Mind \& Language, 8(4), 569-581.

Karmiloff-Smith, A. (1994). Précis of Beyond modularity: a developmental perspective on cognitive science. Behavioral and Brain Sciences, 17, 696-745.

LeFevre, J., Clarke, T., \& Stringer, A. (2002). Influences of language and parental involvement on the development of counting skills: Comparisons of French- and English-speaking Canadian children. Early Child Development and Care, 172, 283-300.

Montague-Smith, A., \& Price, A. (2012). Mathematics in early years education. Abington, Oxon: Routledge.

Mulligan, J., \& Mitchelmore, M. (2009). Awareness of pattern and structure in early mathematical development. Mathematics Education Research Journal, 21(2), 33-49.

Munn, P. (2008). Children's beliefs about counting. In I. Thompson (Ed.), Teaching and Learning Early Number (pp. 19-33). Berkshire: Open University Press.

Resnick, L. (1992). From proroquantities to operators: Building mathematical competence on a foundation of everyday knowledge. In G. Leinhardt, R. Putnam \& R. A. Hattrup (Eds.), Analysis of arithmetic for mathematics teaching (pp. 373-425). Hillsdale, New Jersey: Lawrence Erlbaum Associates.

Rittle-Johnson, B., Siegler, R. S., \& Alibali, M. W. (2001). Developing conceptual understanding and procedural skill in mathematics: an iterative process. Journal of Educational Psychology, 93, 346-362. Rittle-Johnson, B., \& Koedinger, K. R. (2009). Iterating between lessons on concepts and procedures can improve mathematics knowledge. British Journal of Educational Psychology, 79, 483-500.

Siegler, R.S. (2001). Cognition, instruction, and the quest for meaning. In S.M. Carver \& D. Klahr (Eds.), Cognition and Instruction (pp. 195-203). Mahwah, New Jersey: Lawrence Erlbaum Associates.

Siegler, R.S. (2006). Microgenetic analyses of learning. In D. Kuhn \& R. S. Siegler (Eds.), Handbook of Child Psychology (Vol. 2, pp. 464-510). New Jersey: John Wiley \& Sons. 
Siegler, R. S., \& Robinson, M. (1982). The development of numerical understandings. In H. W. Reese \& L. P. Lipsitt (Eds.), Advances in Child Development and Behavior (Vol.16, pp. 241-312). London: Academic Press.

Slavit, D. (1999). The role of operation sense in transitions from arithmetic to algebraic thought. Educational Studies in Mathematics, 37, 251-274.

Sophian, C., Wood, A., \& Vong, K. I. (1995). Making numbers count: the early development of numerical inferences. Developmental Psychology, 31, 263-273.

Sophian, C. (1997). Beyond competence: The significance of performance for conceptual development. Cognitive Development, 12, 281-303.

Sophian, C. (2009). Numerical knowledge in early childhood. In R. E Tremblay, R. G. Barr, R. DeV., Peters \& M. Boivin (Eds.), Encyclopedia of Early Childhood Development. Montreal, Quebec: Centre of Excellence for Early Childhood Development, (pp. 1-7). http://www.childencyclodedia.com/documents/SophianANGxp.pdf. Accessed 23 November 2015.

Star, R. (2007). Foregrounding procedural knowledge. Journal for Research in Mathematics Education, 38(2), 132-135.

Star, R., \& Stylianides, G. J. (2013). Procedural and conceptual knowledge: exploring the gap between knowledge type and knowledge quality. Canadian Journal of Science, Mathematics and Technology Education, 13(2), 169-181.

Tall, D., Gray, E., Bin Ali, M., Crowley, L., DeMarois, P., McGowen, M., Pitta, D., Pinto, M., Thomas, M., \& Yusof, Y. (2001). Symbols and the bifurcation between procedural and conceptual thinking. Canadian Journal of Science, Mathematics and Technology Education, 1(1), 81-104. Thompson, I. (2008). From counting to deriving number facts. In I. Thompson (Ed.), Teaching and Learning Early Number (pp. 97-109). Maidenhead: Open University Press.

Thompson, I., \& Bramald, R. (2002). An investigation of the relationship between young children's understanding of the concept of place value and their competence at mental addition. Report of the Nuffield Foundation. Newcastle upon Tyne, U.K. University of Newcastle upon Tyne.

Threlfall, J. (2008). Development in oral counting, enumeration and counting for cardinality. In I. Thompson (Ed.), Teaching and Learning Early Number (pp. 61-71). Maidenhead: Open University Press.

Threlfall, J., \& Bruce, B. (2007). Just counting: Young children's oral counting and enumeration. European Early Childhood Education Research Journal, 13(2), 63-77.

Voutsina, C. (2012). A micro-developmental approach to studying young children's problem solving behavior in addition. Journal of Mathematical Behavior, 31, 366-381.

Vygotsky, L. S. (1978). Mind in society. Cambridge, MA: Harvard University Press. 